解 説

\title{
Effect of Cooling Rate on Tc and Jc in
}

\section{$\mathrm{YBa} \mathrm{C}_{2} \mathrm{U}_{3} \mathrm{O}_{7-y}$ after sintering}

$\mathrm{YB} \mathrm{a}{ }_{2} \mathrm{Cu}_{3} \mathrm{O}_{7-\nu}$ の T c と J ckおよぼす熱処理時の冷却速度の影響

\author{
Yuichiro KITA**, Yoshitake NISHI*, Akira IGARASHI**, Shigeki TOKUNAGA**, \\ Mamoru KAHAKAMI*
}

* Departmement of Materials Science, Tokai University, 1117, Kitakaname, Hiratsuka, Kanagawa, 259-12, JAPAN; ** Guraduate School of Tokai University

(Recieved 1, March 1990 , Accepted 31, May 1990)

\begin{abstract}
The oxygen concentration in $\mathrm{Y}-\mathrm{Ba}-\mathrm{Cu}-0$ is one of the dominant factors to control the superconducting properties. Since oxygen concentration is controlled by the cooling rate, the cooling rate affects the superconducting properties. The lattice constant of the c-axis is related to oxygen concentration. Thus, we undertook to obtain the change of superconducting properties ( $\mathrm{T} c$ and $\mathrm{Jc}$ ) and the lattiçe constant of the c-axis with the cooling rate in $\mathrm{Y}-\mathrm{Ba}-\mathrm{Cu}-0$. The cooling curves were dominated Newton analysis.

Based on the relaxation theory, we showed the existence of an approximately linear relationship between the lattice constant of the c-axis and the cooling rate, between Tc and the cooling rate and between $\mathrm{Jc}$ at $15 \mathrm{~K}$ and the cooling rate. We conclude that the relaxation theory can be explained by oxygen concentration change in oxygen-deficient perovskite of $\mathrm{Y}-\mathrm{Ba}-\mathrm{Cu}-0$.

The abnormal Jc change is found from 45 to $65 \mathrm{~K}$ for slow cooled specimen. The probable explanation is discussed by two phases. The slow cooled specimen has the ortho-I (matrix) and the ortho-II, the ortho-II can be the pinning site and then causes the abnormal Jc change.
\end{abstract}

key words: superconductor, $\mathrm{Y}-\mathrm{Ba}-\mathrm{Cu}-0$, cooling rate, relaxation theory, Tc, Jc, heat treatment

1.はじめに

$\mathrm{YBa}_{2} \mathrm{Cu}_{3} \mathrm{O}_{7-y}$ は史上初の液体窒素沸点温度 (77.3K) 以上のTcを示す超電導体として発見されて以来(Ref. 1)、物性面、材料面、理論面から非常に多くの研究が 行われていることは周知の通りである。作製法も種々 の方法が提案されているが、焼結法は製作工程が簡単 であり、かつ再現性むよいため、多くの研究に採用さ れている。しかし、焼結法を用いて試料を作製する場 合は、熱処理条件が重要な問題となる。特に、焼結後 の冷却速度を変化させると、結晶中の酸素量を連続的 に制御することが可能であり、これにとすない超電導 特性が変化する。この過程は、 $\mathrm{YBa}_{2} \mathrm{Cu}_{3} \mathrm{O}_{7-y}$ の結晶構 造に起因している。

\section{2 . 結晶構造と酸素量}

$\mathrm{YBa}_{2} \mathrm{Cu}_{3} 0_{7-y}$ の結晶構造の解明は、単結晶 $\mathrm{X}$ 線回折 (Refs. 2, 3)、粉末 X線回折 (Ref.4)、高分解能粉末中 性子線回折 (Refs. 5-9)、超高圧電子顕微鏡観察 (Ref. 10)などによって行われ、酸素久陥を有し、Cu0層 3 層
のペロブスカイト構造であることが明らかにされた。 Fig. 1 に $\mathrm{YBa}_{2} \mathrm{Cu}_{3} \mathrm{O}_{7-\mathrm{y}}$ の結晶構造を示す 11)。Y原 子を含む面上には0原子は存在しない。面上の0原 子は、 $\mathrm{a}$ 軸上の $(1 / 2,0,0)$ に位置する $0(4)$ を主として占 有し、 $(0,1 / 2,0)$ に位置する0(5)の占有率はほぼゼ口 である。このため、、軸の方がb軸よりもやや長い斜方 晶構造をとる。結晶中の酸素量 (7-y) は、熱処理温 度の上昇により減少する。この挙動に関与する0原子 はFig.10の (4)と0(5)である。温度の上昇とともに $0(4)$ 占有率は減少し、逆に0(5)の占有率は増加す る11)。その結果、 $a 、 b$ 両軸の長さは接近し、転移温度 では0(4)、0(5)の占有率が等しくなるため、正方晶と なる。転移温度以上では、 $0(4) 、 O(5)$ 双方から0原子 が等量ずつ抜け出すため、正方晶のまま酸素量が単調 に減少する。したがって、高温において安定な相は正 方晶であり、焼結時にまず生成される結晶は正方晶と なる。また、この変態は可逆的に起こるため、冷却に 際しては結晶中に酸素を取り込み、正方晶から斜方晶 へ変態する。この変態にともなう歪は、双晶を導入す ることにより緩和される 12)。なお、高温から急冷す ると酸素を取り込む間がないため、正方晶、あるいは 酸素量の少ない斜方晶のまま固定される。 
$\mathrm{YBa}_{2} \mathrm{Cu}_{3} \mathrm{O}_{7-y}$ は結晶中の酸素量により超電導特性に 大きな影響をおよぼす 13-17)。酸素量の增加は、 キャリアー濃度を增大させ、TcやJcの增加の原因とな り得る。またNakazawaらは、酸素量が多く90K級のTc をむつ斜方晶をor tho-I 相、酸素量が少なく60K級の Tcをむつ斜方晶をor tho-II相として区別した 18,19)。

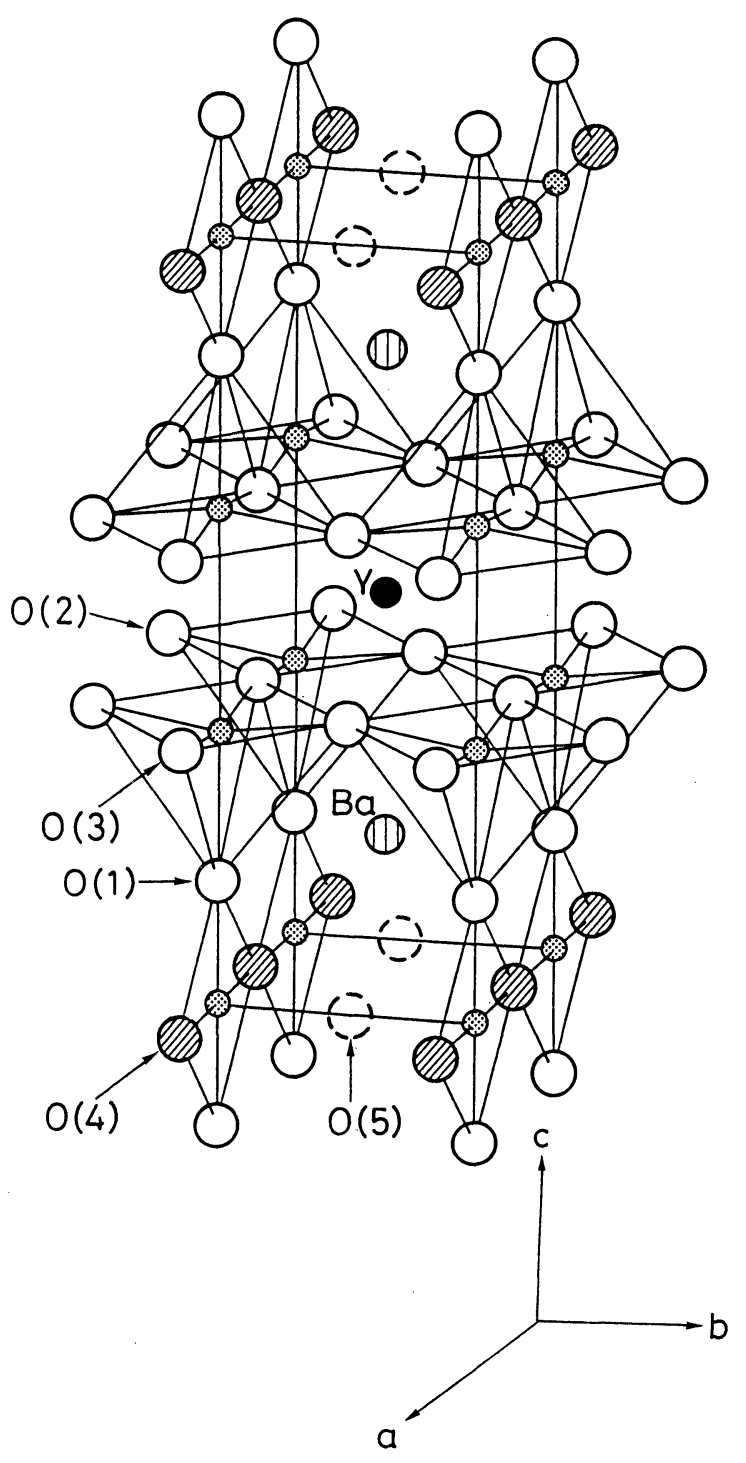

Fig. 2 に冷却速度を制御し酸素量を変化させた、 $\mathrm{YBa}_{2} \mathrm{Cu}_{3} \mathrm{O}_{7-y}$ の電気抵抗率の温度変化を示す。or tho$\mathrm{I}$ 相は、温度の低下とともに電気抵抗率が金属的に低 下する。これに対し、ortho-II相は110Kで極小値を示 した後、上昇する傾向に転じ、80Kで超電導遷移を生 じる。酸素量の少ない正方晶では、ortho- I 相に比べ 電気抵抗率が5析も高く、かつ温度の低下とともに半 導体的に抵抗率が上昇し超電導は得られない20）。

以上の条件から、 $\mathrm{YBa}_{2} \mathrm{Cu}_{3} \mathrm{O}_{7-y}$ の焼結後の冷却速度 を変化させると、0(4)に大る0原子の量が変化し、超 電導特性を決定する重要な因子のひとつとなることが わかる。この過程は、空孔の減少過程とみることがで きる。すなわち、焼結後の冷却速度が速いと酸素が入 りにくく空孔が抜けないが、逆に冷却速度が遅いと酸 素が充分に大り空孔が抜けると考えられる。したがっ て、結晶中の酸素量の変化は結晶における空孔の消減 と同様に、緩和過程に支配されると仮定することがで きる。

そこで、我々は $\mathrm{YBa}_{2} \mathrm{Cu}_{3} \mathrm{O}_{7-\mathrm{y}}$ の焼結後の冷却速度の 変化にとむなう酸素量の変化およびTcについて検討し た。また、Jcについてす興味ある結果が得られたので、 あわせて紹介する。

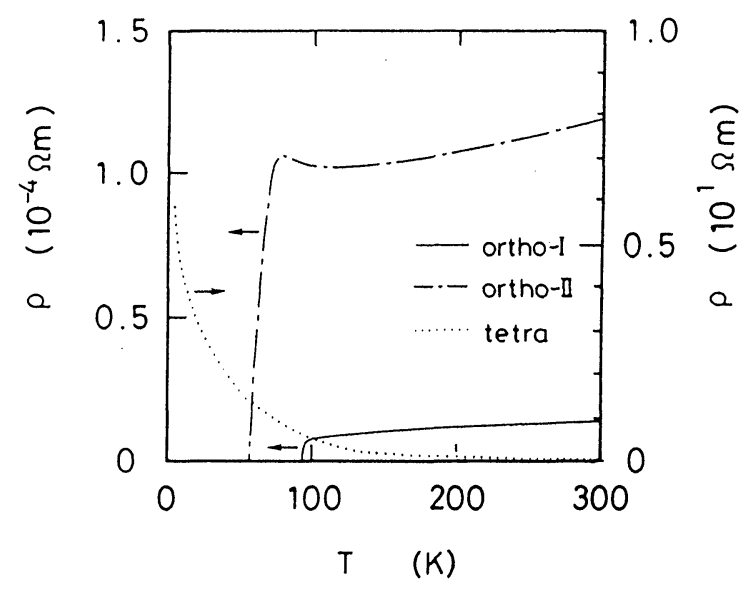

Fig. 2 Temperature dependence on electrical resistivity of $\mathrm{YBa}_{2} \mathrm{Cu}_{3} \mathrm{O}_{7-y}$ at different phases.

\section{3. 実験方法}

試料の作製プロセスをFig. 3 に示す。試料の出発組 成は $\mathrm{YBa}_{2} \mathrm{Cu}_{3} \mathrm{O}_{7-\mathrm{y}}$ とした。原料粉には $\mathrm{Y}_{2} \mathrm{O}_{3}$ (純度 $\left.4 \mathrm{~N}\right) 、$ $\mathrm{BaCO}_{3}$ （純度 $3 \mathrm{~N}$ ）、 $\mathrm{CuO}$ (純度 $3 \mathrm{~N}$ ）を用いた。原料粉は 
充分に混練を行った後、1200Kで $2 \mathrm{hr} 、$ 空気中で仮焼し た。仮焼粉は再度、粉砕、混練し、圧粉成形した。本 焼結は $1200 \mathrm{~K} て ゙ \mathrm{hr}$ 、空気中で行い、その後、種々の冷 却速度で試料を冷却した。試料の冷却に際しては、 ニュートンの冷却条件に従うように制御した 21)。

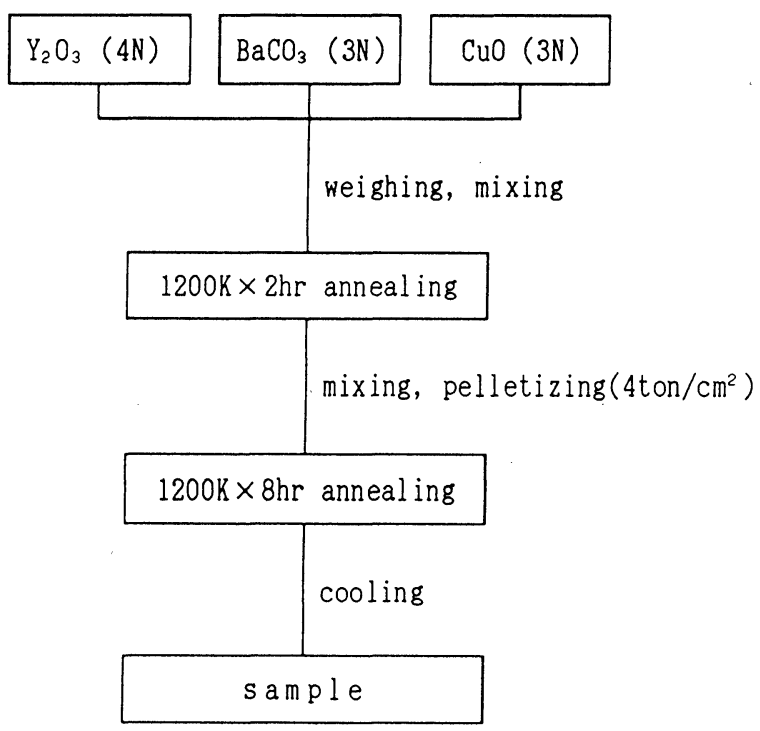

Fig. 3 Flowchart of the sample preparation.

試料の電気抵抗率 $(\rho)$ および臨界温度 (Tc) の測 定には、通常の直流四端子法を用い、端子間電圧は Keithley181ナノボルトメーター（分解能10nV）を用 いて測定した。試料の温度は熱漏れ法によって制御し、 $\mathrm{Au} \cdot \mathrm{Fe}$-クロメル熱電対を試料表面に密着させて測定し た 22)。

試料の構造は、X線回折 $(\mathrm{Cu}-\mathrm{K} \alpha)$ を用いて調べた。

\section{4. 結果および考察}

\section{1 冷却条件}

本焼結後の試料の冷却に際しては、ニュートンの冷 却条件に従うように制御した。ニュートンの冷却条件 むとで、温度 (T) における冷却速度 $(\mathrm{R} ; \mathrm{dT} / \mathrm{dt})$ は次 式によって与えられる 21,23)。

$$
\mathrm{R}=\mathrm{dT} / \mathrm{dt}=-\mathrm{Co}(\mathrm{T}-\mathrm{Ta})
$$

ここで、Coは炉の熱容量に関するパラメーターであり、 Taは冷却後の試料の温度を示している。Fig. 4 に焼結 後の試料の冷却曲線を示す。冷却速度はCoとTaを制御 することによって変化させた。この冷却曲線がニュー トンの泠却条件に適合する場合、Coは温度Tに依存し ない值である。（1）式より（2）式を得る。

$$
\log \operatorname{Tr}=- \text { Co } \mathrm{t} / 2.303
$$

ここで、Trは（3）式に示す温度パラメーターであり、 次式で与えられる。

$$
\mathrm{Tr}=(\mathrm{Te}-\mathrm{Ta}) /\left(\mathrm{T}_{0}-\mathrm{Ta}\right)
$$

ここで、Toは冷却開始前（ $t=0 ）$ の焼結温度（1200K）、 $\mathrm{Te}$ は冷却時間 $\mathrm{t}$ における温度である。（1）、（2）式 より次式を得る。

$$
\mathrm{dT} / \mathrm{dt}=-2.303(\mathrm{~T}-\mathrm{Ta}) \mathrm{d} \log \mathrm{Tr} / \mathrm{dt}
$$

冷却曲線がニュートンの冷却条件に適合する場合に は、各温度における正確な冷却速度は、（4）式から 得られる。また、 $109 \operatorname{Tr}$ と の間に直線関係が得られ るなら、ニュートンの冷却条件に適合していることが わかる。Fig. 5 は冷却時間 $(t)$ に対する温度パラ メーター（Tr）の変化を示している。図中、tに対し $\operatorname{Tr}$ の対数が直線関係を示しており、本研究における試 料は、ニュートンの冷却条件に従って冷却されたこと を示す。

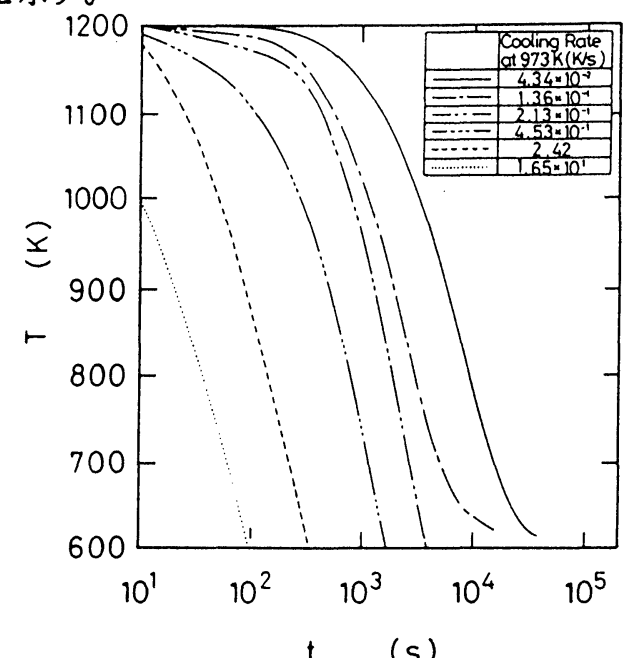

Fig. 4 Change in temperature ( $T$ ) against logarithmic cooling time $(\log t)$ at different cooling conditions for $\mathrm{YBa}_{2} \mathrm{Cu}_{3} \mathrm{O}_{7-y}$. 


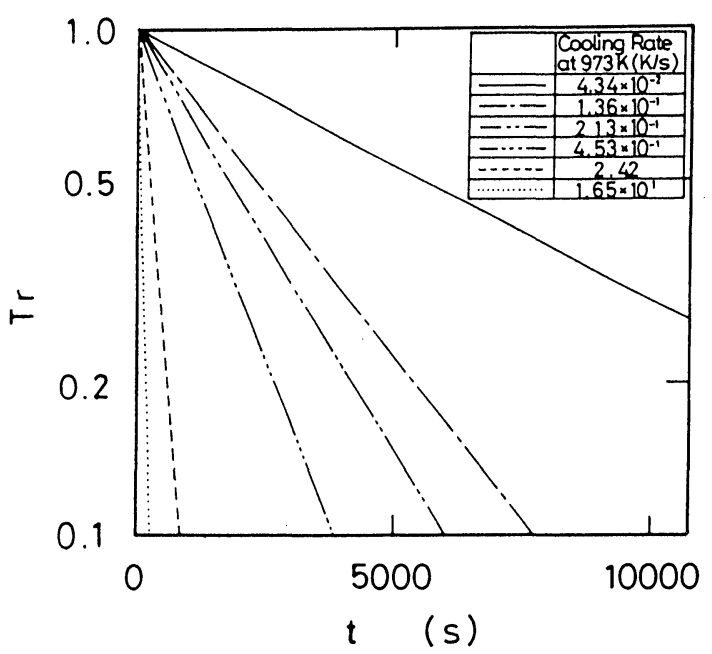

Fig. 5 Change in logarithmic reduced temperature ( $\log \mathrm{Tr}$ ) against cooling time $(t)$ at different cooling conditions for $\mathrm{YBa}_{2} \mathrm{Cu}_{3} \mathrm{O}_{7-y}$.

\section{2 冷却速度と $\mathrm{c}$ 軸の格子定数}

$\mathrm{YBa}_{2} \mathrm{Cu}_{3} \mathrm{O}_{7-y}$ の結晶の $\mathrm{c}$ 軸の格子定数は、酸素量 (7-y) によって変化し、Onokより（5）式に示すよ うな直線関係が報告されている 24）。

$$
(7-y)=-5.454 c+70.512
$$

そこで、冷却速度 (R) と c 軸の格子定数 (c) の間に 緩和関数が成立すると仮定すると、次式が成立する。

$$
X=\left\{\left(c-{ }^{0} c\right) /\left({ }^{r} c-{ }^{0} c\right)\right\}=\exp \left(-k_{1} / R\right)
$$

ここで、Xは物性の変化率であり、 ${ }^{0} \mathrm{c}$ の物理的意味は 緩和過程より導出される冷却速度が限りなく遅いとき の c 軸の格子定数、 ${ }^{\mathrm{r}} \mathrm{c}$ は逆に冷却速度が限りなく速い ときの $\mathrm{c}$ 軸の格子定数を示している。（6）式を変形 すると次式を得る。

$$
\log \left(c-{ }^{0} c\right)=-k_{1} / 2.303 R+\log \left({ }^{x} c-{ }^{0} c\right)
$$

したがって緩和過程に従うなら、（7）式の左辺と 1/Rの間には直線関係が成立する。そこで、Fig.6に ${ }^{0} \mathrm{c}$ 值を変化させ、（7）式における $\mathrm{c}$ 軸の格子定数 の実測値の相関係数 (F) の変化を調べた結果を示す。 この結果より、相関係数が最む良くなる值を ${ }^{0} \mathrm{c}$ と、
${ }^{0} \mathrm{C}=11.6740(\AA)$ を得た。

Fig. 7 に、 ${ }^{0} \mathrm{c}=11.6740$ ( $\AA$ ) における（7）式の左 辺と $1 /$ Rの関係を示す。このようにc 軸の格子定数と 冷却速度の間には次式に示す緩和関数が成立すること がわかる。

$$
\begin{aligned}
\log \left(\mathrm{c}-{ }^{0} \mathrm{c}\right) & =-\mathrm{k}_{1} / 2.303 \mathrm{R}+\log \left({ }^{\mathrm{r}} \mathrm{c}-{ }^{0} \mathrm{c}\right) \\
& =-1.391 \times 10^{-1} / \mathrm{R}-1.495
\end{aligned}
$$

また、（8）式より $\left.{ }^{\mathrm{r}} \mathrm{c}=11.7058 （ \AA\right)$ が得られる。 以上の結果から、Fig. 8 に示すような冷却速度と C 軸の格子定数の関係が得られる。図中実線は、（8） 式の緩和関数を示している。

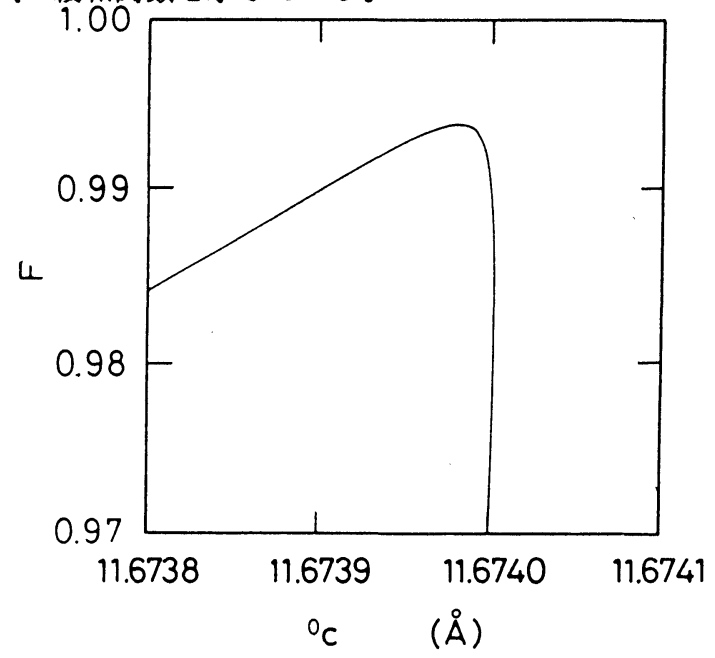

Fig. 6 Change in correlation coefficient (F) with the lattice constant of c-axis (c). When cooling rate is very slow, $c$ approaches to ${ }^{\circ} \mathrm{c}$.

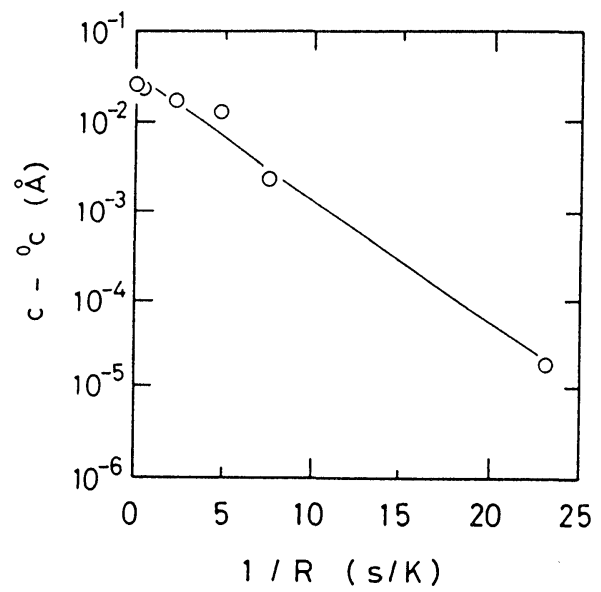

Fig. 7 Linear plot between $\left(c-{ }^{0} \mathrm{c}\right)$ and reciprocal cooling rate $(1 / \mathrm{R})$ of $\mathrm{YBa}_{2} \mathrm{Cu}_{3} \mathrm{O}_{7-\mathrm{y}}$. c is the lattice constant of c-axis. When $R$ is very slow, $c$ approaches to ${ }^{\circ} \mathrm{c}$. 


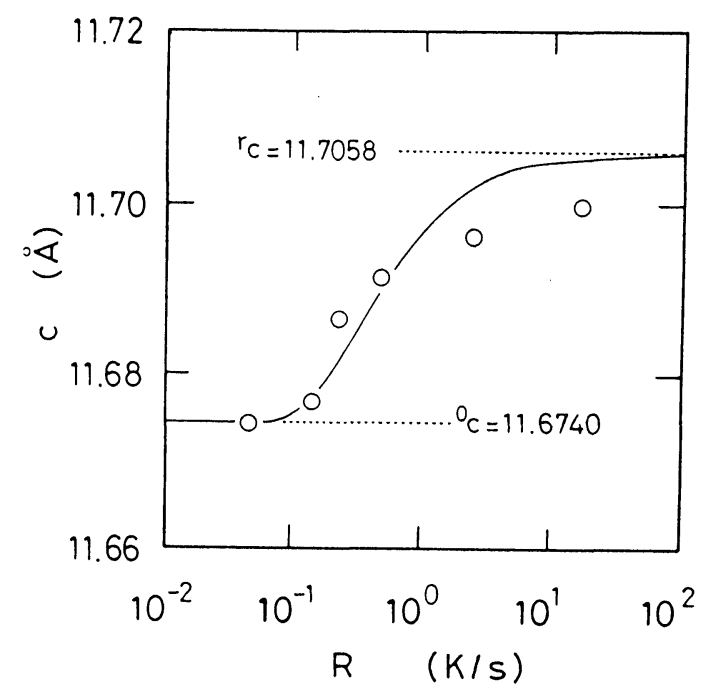

Fig. 8 Change in the lattice constant of c-axis (c) against cooling rate $(R)$. Solid line is calculated by eq. ( 8 ). When $R$ is very slow, $c$ approaches ${ }^{\circ} \mathrm{C}$. When $R$ is very fast, $c$ approaches to ${ }^{\mathrm{r}} \mathrm{c}$.

\section{4 . 3 冷却速度と T c}

$\mathrm{YBa}_{2} \mathrm{Cu}_{3} \mathrm{O}_{7-y}$ は結晶中の酸素量によってTcが変化す る 13-16)。したがって、Tcの変化もc 軸の格子定数 と同様に、緩和過程に支配されるのではないかと考え られる。そこで、ortho-I 相における冷却速度 (R) と $\mathrm{Tc}_{\mathrm{mid}}$ の間に緩和関数が成立すると仮定すると、

（9）式が成立すると考えられる。

$$
\begin{aligned}
& \log \left({ }^{0} \mathrm{TC}_{\mathrm{mid}}-\mathrm{TC}_{\mathrm{mid}}\right) \\
= & -\mathrm{k}_{2} / 2.303 \mathrm{R}+\log \left({ }^{0} \mathrm{~T} \mathrm{c}_{\mathrm{mid}}-{ }^{r} \mathrm{TC}_{\mathrm{mid}}\right)
\end{aligned}
$$

ここで、 ${ }^{\circ} \mathrm{Tc}_{\mathrm{m} / \mathrm{d}}$ の物理的意味は緩和過程より導出され る冷却速度が限りなく小さいときの $\mathrm{Tc}_{\mathrm{m} I \mathrm{~d}}$ を示してお り、c 軸の格子定数同様、各 $\mathrm{T}_{\mathrm{m} / \mathrm{d}}$ の実測値の相関係 数が最む良くなる値とした。Fig. 9 に ${ }^{0} \mathrm{Tc}_{\mathrm{m} / \mathrm{d}}$ の值を变 化させ、（9）式における $\mathrm{Tc}_{\mathrm{m} i d}$ の実測值の相関係数 （F）の変化を調べた結果を示す。この結果より、 ${ }^{0} \mathrm{TC}_{\mathrm{mid}}=93.87(\mathrm{~K})$ とした。また、 ${ }^{\mathrm{r}} \mathrm{TC}_{\mathrm{m} \text { id }}$ は逆に冷却 速度が限りなく大きいときの $\mathrm{Tc}_{\mathrm{m} \text { id }}$ を示している。

Fig. 10 (9) 式の左辺と $1 /$ Rの関係を示す。図中 実線は (10) 式の緩和関数を示しており、 $\mathrm{Tc}_{\mathrm{m} \text { id }}$ の実 測值がいずれも緩和関数で整理しうることがわかる。

$$
\begin{aligned}
& \log \left({ }^{0} \mathrm{Tc}_{\mathrm{mid}}-\mathrm{Tc}_{\mathrm{m} \mid \mathrm{d}}\right) \\
= & -\mathrm{k}_{2} / 2.303 \mathrm{R}+\log \left({ }^{0} \mathrm{Tc}_{\mathrm{m} i d}-{ }^{r} \mathrm{Tc}_{\mathrm{m} \mid \mathrm{d}}\right) \\
= & -9.211 \times 10^{-2} / \mathrm{R}+0.9945
\end{aligned}
$$

また、（10）式より ${ }^{\mathrm{r}} \mathrm{Tc}_{\mathrm{m} i \mathrm{~d}}=83.99(\mathrm{~K})$ が得られる。 以上の結果から、Fig. 11 に示すようなor tho-I 相 の冷却速度と $\mathrm{Tc}_{\mathrm{m} i \mathrm{~d}}$ の関係が得られる。なお、黒丸で 示されるさらに冷却速度の速い試料は、or tho-II相の 試料を示しており、（10）式に示すortho-I 相の緩和 過程とは異なっていることがわかる。

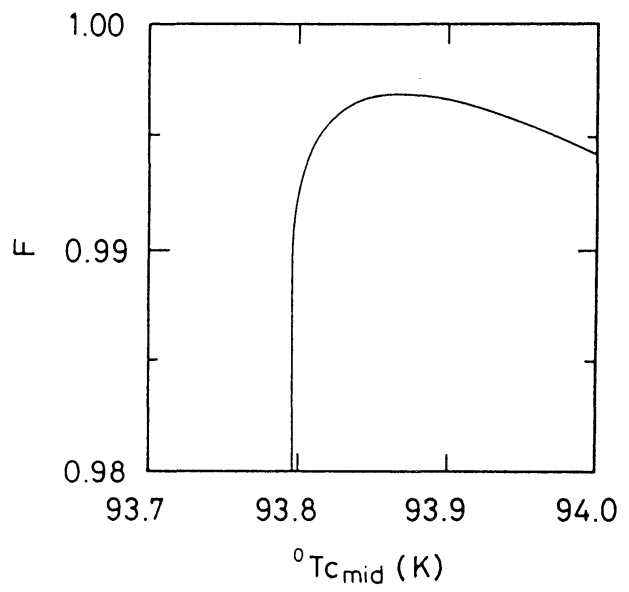

Fig. 9 Change in correlation coefficient (F) with midpoint temperature of superconducting transition $\left(\mathrm{TC}_{\mathrm{m} i \mathrm{~d}}\right)$. When cooling rate is very slow, $\mathrm{Tc}_{\mathrm{mid}}$ approaches to ${ }^{0} \mathrm{Tc}_{\mathrm{mid}}$.

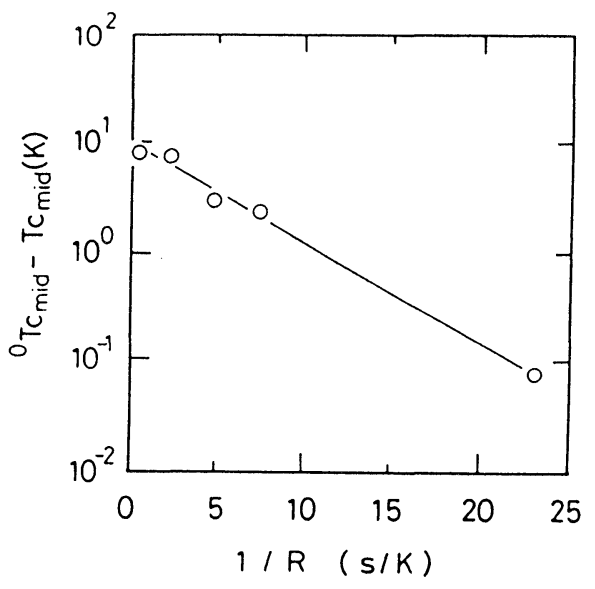

Fig. 10 Linear plot between $\left({ }^{0} \mathrm{Tc}_{\mathrm{m} / \mathrm{d}}-\mathrm{Tc}_{\mathrm{m} / \mathrm{d}}\right)$ and reciprocal cooling rate $(1 / R)$ of $\mathrm{YBa}_{2} \mathrm{Cu}_{3} \mathrm{O}_{7-y}$. $T c_{m i d}$ is midpoint temperature of superconducting transition. When $R$ is very slow, $T c_{m i d}$ approaches to ${ }^{\circ} \mathrm{Tc}_{\mathrm{mid}}$. 


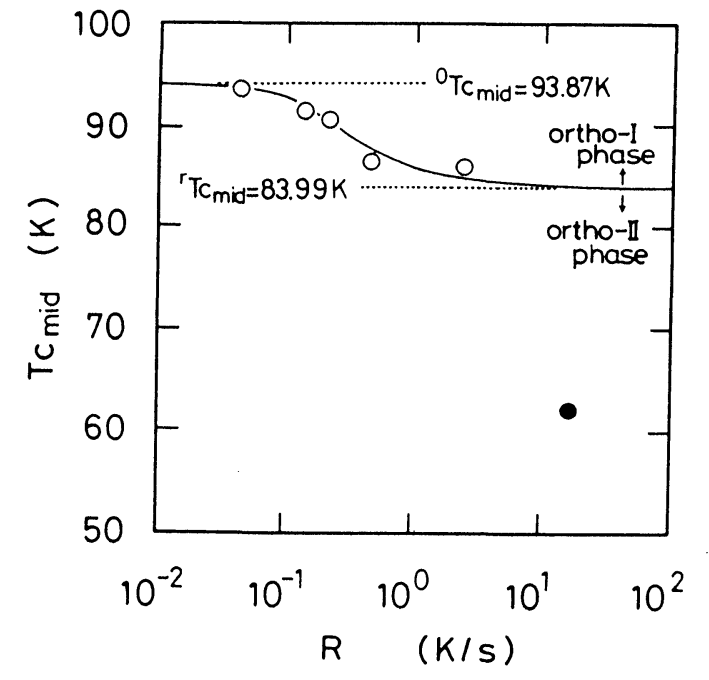

Fig. 11 Change in midpoint temperature of superconducting transition $\left(T c_{m i d}\right.$ ) against cooling rate $(1 / R)$. Solid line is calculated by eq. (10). When $R$ is very slow, $T c_{m} I d \ldots$. approaches to ${ }^{0} T \mathrm{c}_{\mathrm{m} i \mathrm{~d}}$. When $R$ is very fast, $T \mathrm{c}_{\mathrm{m} I \mathrm{~d}}$ approaches to ${ }^{\mathrm{r}} \mathrm{Tc}_{\mathrm{m} i \mathrm{~d}}$.

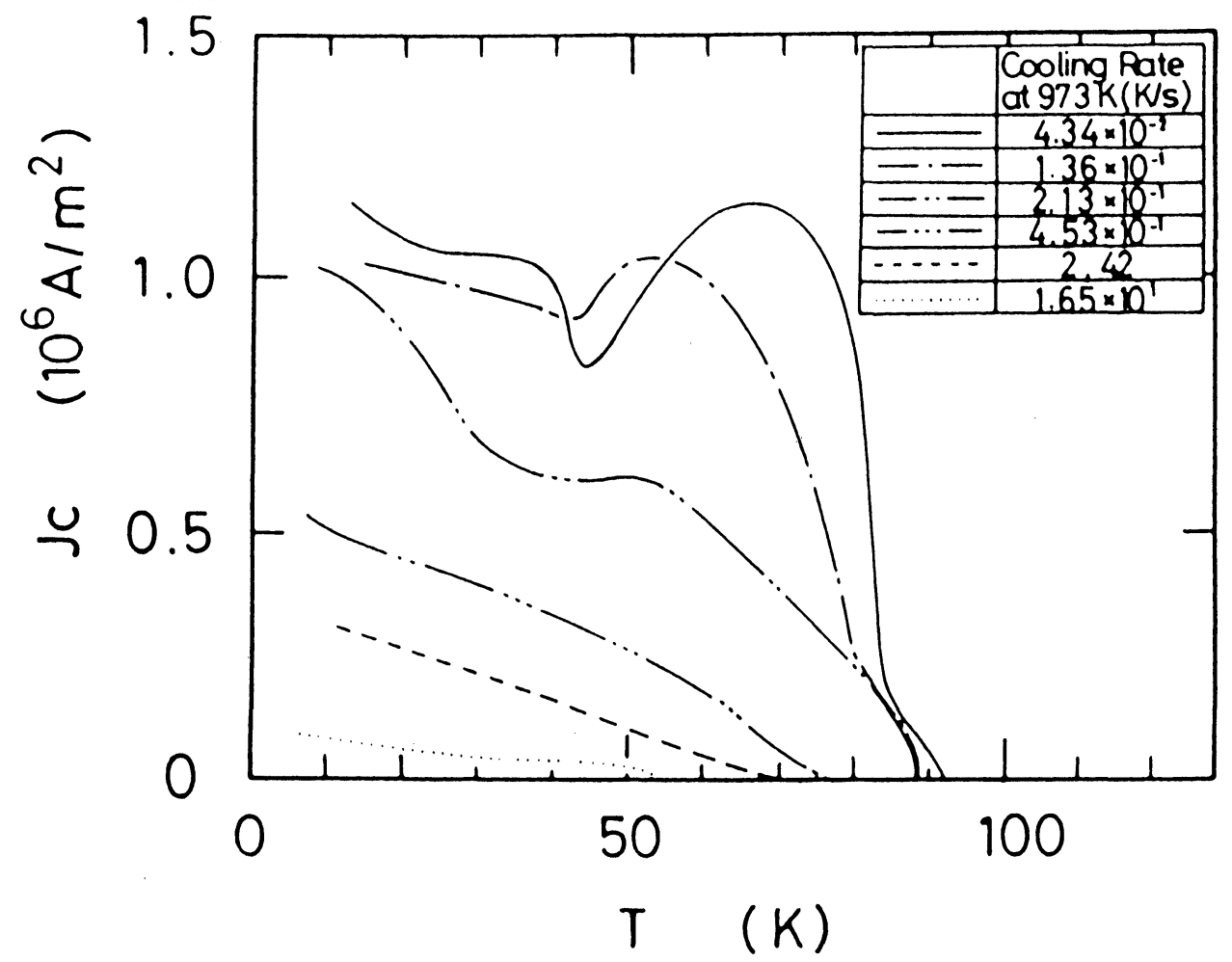

Fig. 12 Temperature dependence on $\mathrm{Jc}$ of $\mathrm{YBa}_{2} \mathrm{Cu}_{3} \mathrm{O}_{7-y}$ at different cooling rates.
Fig. 12 に冷却速度の異なる試料のJcの温度依存を 示す。冷却速度の速い試料ではJcは小さく、温度の低 下にとむないJcが単調に增加する、一般的な傾向を示 した。これに対し冷却速度の遅い試料では、Jcは大き く、65K付近でJcの異常な增加がみられだ。また、こ のJcの異常は、冷却速度の遅い試料ほど著しくなって いることがわかる。

これは、 $\mathrm{YBa}_{2} \mathrm{Cu}_{3} \mathrm{O}_{7-\mathrm{y}}$ の超電導相が90K級の高Tcを示 すor tho-I 相と、60K級の低Tcを示すor tho-II相の 2 相から棈成されているためではないかと考えられる。 すなわち、冷却速度の遅い試料はor tho-I 相のマト リックスにortho-I相が分散しているため、65K付近 では常電導相であるor tho-II 相がピンニングサイトと しての効果を示し、Jcの変則的な上昇がみられたので はないかと考えられる 25)。

$15 \mathrm{~K}$ におりる $\mathrm{Jc}\left(\mathrm{Jc}_{15 \mathrm{~K}}\right)$ は冷却速度 $(\mathrm{R})$ を制御す ることによって変化するので、 $\mathrm{R}$ こ $\mathrm{Jc}_{15 \mathrm{~K}}$ の間に緩和関 数が成立すると仮定すると次式が成立する。

$$
\begin{aligned}
& \log \left(\log ^{0} \mathrm{Jc}_{15 \mathrm{~K}}-\log \mathrm{Jc}_{15 \mathrm{~K}}\right) \\
= & -\mathrm{k}_{3} / 2.303 \mathrm{R}+\log \left(\log ^{0} \mathrm{Jc}_{15 \mathrm{~K}}-\log ^{\mathrm{r}} \mathrm{Jc}_{15 \mathrm{~K}}\right)
\end{aligned}
$$


ここで、 ${ }^{0} \mathrm{Jc}_{15 \mathrm{~K}}$ の物理的意味は緩和過程より導出され る冷却速度が限りなく小さいときの $\mathrm{Jc}_{15 \mathrm{~K}}$ を示してお り、c 軸の格子定数および $\mathrm{T} \mathrm{c}_{\mathrm{m} / \mathrm{d}}$ と同様、各 $\mathrm{Jc}_{15 \mathrm{~K}}$ の実 測値の相関係数が最す良くなる值とした。Fig. 13 に ${ }^{0} \mathrm{Jc}_{15 \mathrm{~K}}$ の值を变化させ、（11）式における $\mathrm{Jc}_{15 \mathrm{~K}}$ の実 測値の相関係数 (F) の変化を調べた結果を示す。こ の結果より、 ${ }^{0} \mathrm{Jc}_{15 \mathrm{~K}}=1.13 \times 10^{6}\left(\mathrm{~A} / \mathrm{mm}^{2}\right)$ とした。ま た、 ${ }^{r} \mathrm{Jc}_{15} \mathrm{k}$ は逆に冷却速度が限りなく大きいときの

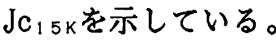

Fig. 14 に（11）式の左辺と1/Rの関係を示す。図 中実線は（12）式の緩和関数を示しており、 $\mathrm{Jc}_{15 \mathrm{~K}}$ の 実測值がいずれす緩和関数で整理しうることがわか る26)。

$$
\begin{gathered}
\log \left(\log ^{0} \mathrm{Jc}_{15 \mathrm{~K}}-\log \mathrm{Jc}_{15 \mathrm{~K}}\right) \\
=-1.955 \times 10^{-1} / \mathrm{R}-3.006 \times 10^{-2}
\end{gathered}
$$

また、（12）式より $\mathrm{Jc}_{15 \mathrm{~K}}=1.32 \times 10^{5}\left(\mathrm{~A} / \mathrm{m}^{2}\right)$ が得ら れる。以上の結果から、Fig. 15 に示すような冷却速 度と $\mathrm{Jc}_{15 \mathrm{~K}}$ の関保が得られる。

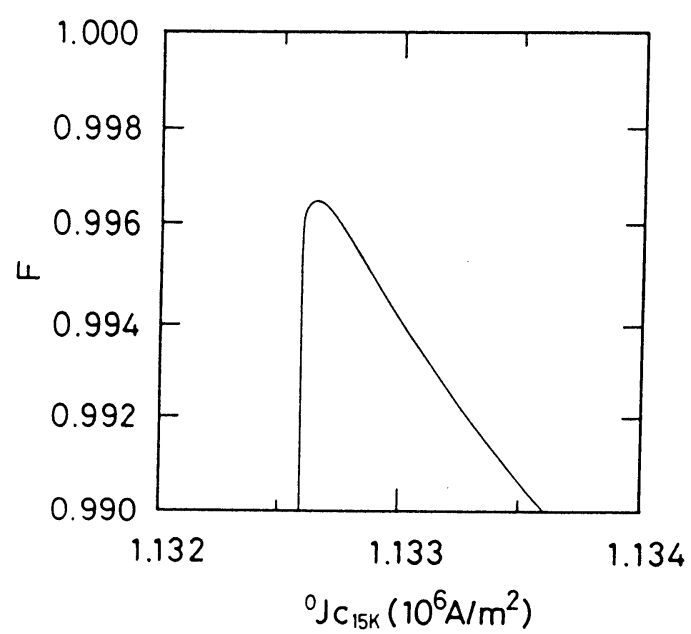

Fig. 13 Change in correlation coefficient (F) with superconducting critical current densities at $15 \mathrm{~K}\left(\mathrm{Jc}_{15 \mathrm{~K}}\right)$. When cooling rate is very slow, $\mathrm{Jc}_{15 \mathrm{~K}}$ approaches to ${ }^{0} \mathrm{Jc}_{15 \mathrm{~K}}$.

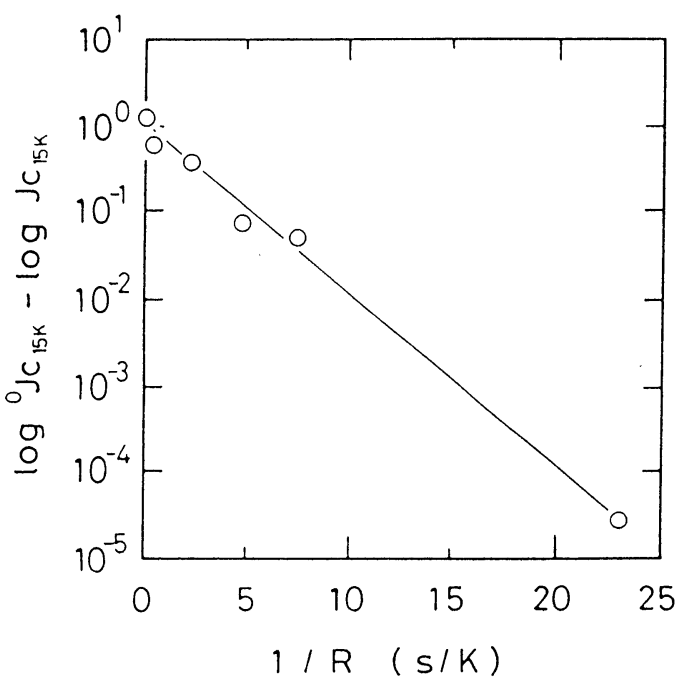

Fig. 14 Linear plot between $\left(\log _{10}{ }^{0} \mathrm{Jc}_{15 \mathrm{~K}^{-}}\right.$ $\left.\log _{10} \mathrm{JC}_{15 \mathrm{~K}}\right)$ and reciprocal cooling rate $(1 / \mathrm{R})$ of $\mathrm{YBa}_{2} \mathrm{Cu}_{3} \mathrm{O}_{7-y} . \mathrm{Jc}_{15 \mathrm{~K}}$ is superconducting critical current densities at $15 \mathrm{~K}$. When $\mathrm{Jc}_{15 \mathrm{~K}}$ is very slow, $\mathrm{Jc}_{15 \mathrm{~K}}$ approaches to ${ }^{0} \mathrm{Jc}_{15 \mathrm{~K}}$.

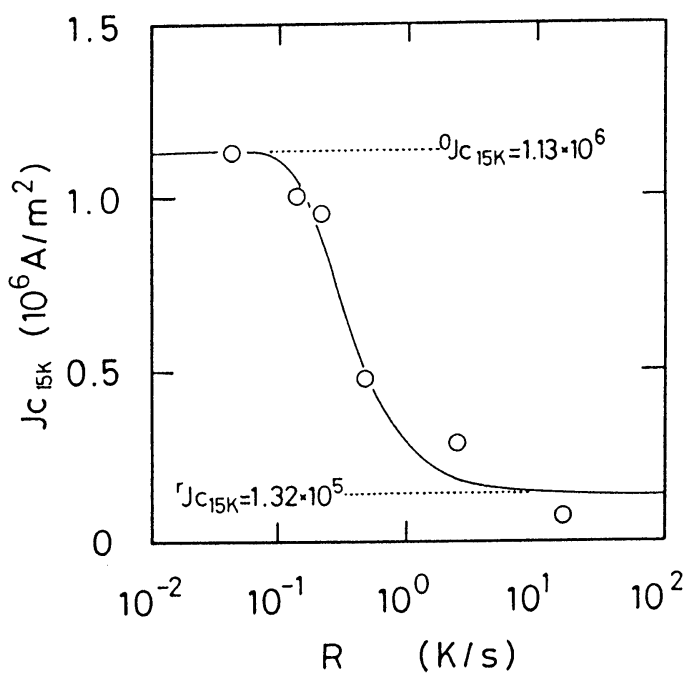

Fig. 15 Change in superconducting critical current densities at $15 \mathrm{~K}\left(\mathrm{JC}_{15 \mathrm{~K}}\right)$ against cooling rate $(1 / R)$. Solid line is calculated by eq. (12). When $R$ is very slow, $\mathrm{Jc}_{15 \mathrm{~K}}$ approaches to ${ }^{0} \mathrm{Jc}_{15 \mathrm{~K}}$. When $R$ is very fast, $\mathrm{Jc}_{15 \mathrm{~K}}$ approaches to ${ }^{r} \mathrm{Jc}_{15 \mathrm{~K}}$. 


\section{5.おわりに}

$\mathrm{YBa}_{2} \mathrm{Cu}_{3} \mathrm{O}_{7-y}$ の超電導特性におよぼす焼結後の冷却 速度の影響について検討を行った。焼結後の泠却速度 を制御することによって、結晶の C 軸の格子定数、Tc、 Jcが変化することが明らかになった。冷却速度に対し $\mathrm{c}$ 軸の格子定数、 $T \mathrm{C}_{\mathrm{m} \text { id }}$ 、15KにおけるJcの值はいずれ も緩和関数で整理しうることが確認された。冷却速度 の遅い焼結体において、65K付近で Jcの異常な增加が みられた。この現象は、冷却速度が遅い試料ほど著し くなっていることがわかった。

References

1) M.K. Wu, J.R.Ashburn, C.J.Torng, P.H.Hor, R.L.Meng, L.Gao, Z.J.Huang, Y.Q. Hang and C.W. Chu: Phys.Rev.Lett., 58(1987), 908.

2) T.Siegrist, S.Sunshine, D.W.Murphy, R.J.Cava and S.M.Zahurak: Phys. Rev., B35(1987),7137.

3) P.F.okamura, S.Sueno, I. Nakai and A.Ono: Mater.Res.Bull., 22(1987), 1081.

4) F. Izumi, H.Asano, T. Ishigaki, A.Ono and F.P.O kamura: Jpn.J.Appl.Phys., 26(1987), L611.

5) M.A.Beno, L.Soderholm, D.W.Capone II, D.G. Hinks, J.D. Jorgensen, J.D.Grace, I.K.Schuller, C.U.Segra and K.Zhang: Appl.Phys.Lett., 51 (1987), 57.

6) F. Izumi, H.Asano, T.Ishigaki, E.TakayamaMuromachi, Y.Uchida, N. Watanabe and T.Nishikawa: Jpn.J.Appl. Phys., 26(1987), L649.

7) W.I.F.David, W.T.A.Harrison, J.M.F.Gunn, O.Moze, A.K.Soper, P.Day, J.D.Jorgensen, D.G. Hinks, M.A.Beno, L.Soderholm, D. W. Capone II, I.K.Schuller, C.U.Segre, K.Zhang and J.D.Grace: Nature, 327(1987), 310.

8) J.J.Capponi, C.Chaillout, A.W. Hewat, P.Lejay, M. Marezio, N.Nguyen, B. Raveau, J.L.Soubeyroux, J.L.Tholence and R.Tournier: Europhys. Lett., 3(1987), 1301.

9) H.You, R.K.McMullan, J.D.Axe, D.E.Cox, J.Z. Liu, G.W.Crabtree and D.J.Jam: Solid State Commun., 62(1987), 479.
10) K.Hiraga, D.Shindo, M.Hirabayashi, M.Kikuchi, K.Oh-ishi and Y.Syono: Jpn.J.Appl. Phys., 26(1987), L1071.

11) J.D.Jorgensen, M.A.Beno, D.G.Hinks, L. Soderholm, K.J.Volin, R.L.Hitterman, J.D. Grace, I.K.Schuller, C.U.Segre, K.Zhang and M.S. Kleef isch: Phys. Rev., B36(1987), 3608.

12) Y.Syono, M.Kikuchi, K.Oh-ishi, K.Hiraga, H.Arai, Y.Matsui, N. Kobayashi, T.Sasaoka and Y. Muto: Jpn. J.Appl. Phys., 26(1987), L498.

13) E. Takayama-Muromachi, Y.Uchida, M. Ishii, T. Tanaka and K. Kato: Jpn.J.Appl.Phys., 26(1987), L1156.

14) H. Oyanag i, H. Ihara, T. Matsubara, M. Tokumoto, T. Matsushita, M.Hirabayashi, K. Murata, N.Terada, T. Yao, H. Iwasaki and Y.Kimura: Jpn.J.Appl.Phys., 26(1987), L1561.

15) M. Tokumoto, H. I hara, T . Mat subara, M.Hirabayashi, N.Terada, H.Oyanagi, K. Murata and Y. Kimura: Jpn.J.Appl.Phys., 26(1987), L1565.

16) P. Monod, N.Ribault, F.D'Yvoir, J. Jegoudez, G.Collin and A.Revcolevschi: J.Phys., 48(1987), 1369.

17) N.M.Alford, H.J.Clegg, M.A.Harmer, J.D. Birchall, K.Kendall and D.H.Jones: Nature, 332(1988), 58.

18) Y.Nakazawa, M. Ishikawa, T.Takabatake, H. Takeya, T.Shibuya, K.Terakura and F. Takei: Jpn. J.Appl.Phys., 26(1987), L682.

19) Y. Nakazawa, M. Ishikawa, T.Takabatake, K. Koga and K. Terakura: Jpn. J.Appl.Phys., 26(1987), L796. 20) T.Hatano, A.Mutsushita, K. Nakamura, Y.Sakka, T. Matsumoto and K.0gawa: Jpn.J.Appl.Phys., 26(1987), L721.

21) Y.Nishi, Y.Kita, A.Igarashi and S.Tokunaga, J. Mater.Sci.Lett., 7(1988), 279.

22) L.L.Sparks and R.L.Powell, J.Research N.B.S., 76A(1972), 263.

23) P.Predecki, A.W.Mullendore and N.J.Grant, Trans. Met. Soc. AIME., 233(1965), 1581.

24) A. Ono: Jpn.J.Appl.Phys., 26(1987), L1223.

25) Y.Nishi, S.Tokunaga, A.Kakiuchi and T. Toyama, Phys. Lett. A128 (1988), 100.

26) Y.Nishi, Y.Kita, A.Igarashi, Tokunaga, J. Mater.Sci.Lett., 8(1989), 503. 